\title{
Active and Passive Microwave Determination of the Circulation and Characteristics of Weddell and Ross Sea Ice
}

\author{
Mark R. Drinkwater and Xiang Liu \\ Jet Propulsion Laboratory, California Institute of Technology \\ 4800 Oak Grove Drive, CA 91109 , USA
}

Tel: 818-354 8189; Fax: 818-393 6720; Email: M.Drinkwater@jpl.nasa.gov

\begin{abstract}
A combination of satellite microwave data sets are used in conjunction with ECMWF and NCEP meteorological analysis fields to investigate seasonal variability in the circulation and sea-ice dynamics of the Weddell and Ross Seas. Results of sea-ice tracking using SSM/I, Scatterometer and SAR images are combined with in-situ data derived from Argos buoys and GPS drifters to validate observed drift patterns. Seasonal 3-month climatologies of ice motion and drift speed variance illustrate the response of the sea-ice system to seasonal forcing. A melt-detection algorithm is used to track the onset of seasonal melt, and to determine the extent and duration of atmospherically-led surface melting during austral summer. Results show that wind-driven drift regulates the seasonal distribution and characteristics of sea-ice and the intensity of the cyclonic Gyre circulation in these two regions.
\end{abstract}

\section{INTRODUCTION}

Dynamic and thermodynamic processes in the Southern Ocean control northward advection of sea-ice and the growth processes that rapidly replace ice in openings in the displaced and dislocated ice cover. Basin-scale ice dynamics limit the geographic distribution of lead fractures and polynyas, while at the same time regulating spatiotemporal variability in ocean-atmosphere heat fluxes. The seasonally evolving sea-ice cover has a significant impact on water-mass modification processes, particularly in the Weddell and Ross Sea basins. In these two regions of focus, ice formation and seasonal melting influence upper-ocean stability through changes in the horizontal and vertical salinity and buoyancy gradients. Ice formation in polynyas can induce convective overturning or seasonal melting can stabilize the mixed layer. Both can have an impact on key processes driving the global thermohaline ocean circulation.

Traditionally, instrumented buoys [1] and models [2] have been used to try to understand large-scale sea-ice processes. But, to-date Antarctic drifting buoy deployments have been limited in time and space (Fig. 1). Using these data, it is difficult to accurately quantify seasonally varying basin-scale ice dynamics and surface forcing experienced by the ice cover, or to validate the new generation of fineresolution coupled ice-ocean models.

Recent developments in processing and gridding ERS-1/2 Wind Scatterometer (ESCAT) and NASA Scatterometer (NSCAT) data [3, 4) allow them to be exploited with existing SSM/I data in the study of Antarctic sea-ice variability. Techniques have also matured for tracking sea-ice drift in Antarctic Synthetic Aperture Radar (SAR) [5], ERS- $1 / 2$ and NSCAT Scatterometer $[6,4]$, and SSM/I images $[7,8,9$, $10,11]$.

\section{DATA SETS}

Collocated Weddell and Ross Sea satellite microwave remote sensing data from (a) SSM/I, (b) ESCAT and ERS-1/2 SAR, and (c) NSCAT were used in this study. For illustration of large-scale dynamics, simultaneous gridded ice-motion data (at 1,3 and 6 day intervals) from Scatterometer and SSM/I are shown tor the entire year of 1992 . Coincident field-deployed Argos buoy and drifting ice camp GPS positions in Figure 1 are presently used to check the validity of tracked

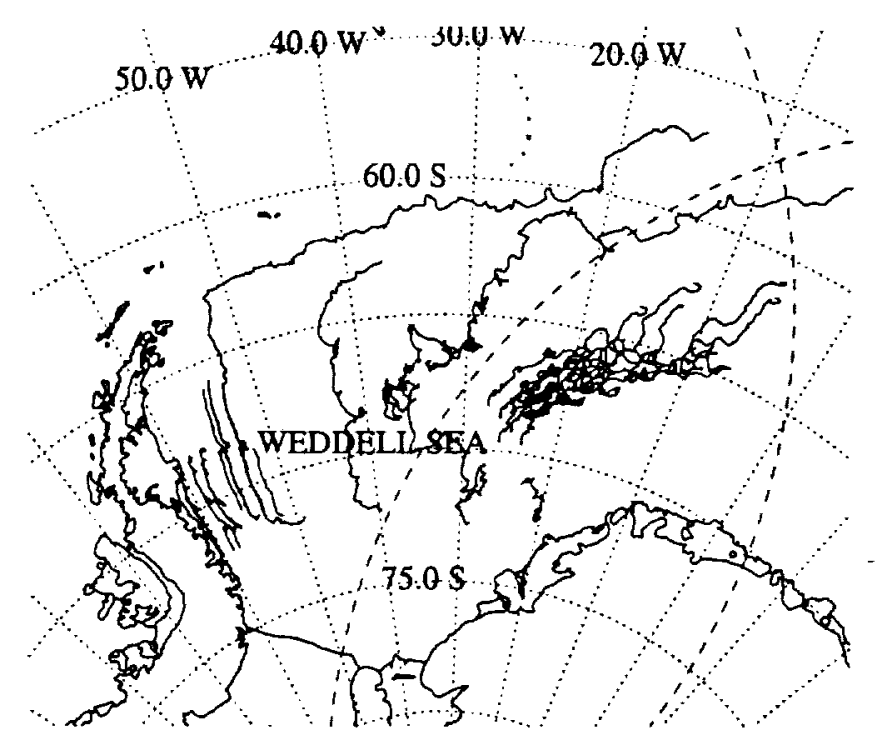

Figure 1. Trajectories of Ice Station Weddell (GPS) and buoys deployed during 1990-1993 in the Weddell Sea, Antarctica [courtesy S. Ackley, D. Martinson, T. Vihma and C. Kottmeier].

drift vectors from each instrument. Temporally and spatially overlapping SAR motion vector grids have been employed for comparison purposes in order to compare the consistency between the derived small and large-scale motion fields. ECMWF and NCEP meteorological analyses and land station data were used to illustrate synoptic-scale atmospheric forcing.

\section{ICE DYNAMICS}

Comparisons between gridded SSM/I ice-drift vectors and ECMWF/NCEP analyses (Fig 2) indicate that daily, or longer timescale large-scale sea-ice circulation in the Weddell and Ross basins, is governed by geostrophic winds driven by seasonally varying mean, synoptic pressure patterns. Higher-frequency, sub-daily drift fluctuations, caused by swift moving low-pressure systems and tidal forcing (over shallow-water continental shelf regions only), and captured only by SAR ice tracking on time-scales of 12 hours or less [5], is not considered here. Comparisons between daily $85 \mathrm{GHz}$ SSM/Itracked drift and buoy data indicate a Gaussian error distribution and near-zero mean bias, with $x, y$ displacement errors of $\sim 7 \mathrm{~km}$ in $4 x$ oversampled data. Results indicate that $\mathrm{rms}$ ertors are reduced in proportion to $1 / \mathrm{V} n$ when the tracking interval or temporal averaging is performed, with an $x, y$ rms error for the 6-day mean motion fields of - $4 \mathrm{~km}$. This is a significant improvement over 1-day fields, but nevertheless suggests that seasonal climatologies are a far more suitable solution than offering daily motion fields at the present time. Comparisons of daily drift and 24 hour mean ECMWF or NCEP pressure and wind fields also indicate offsets between synoptic lowpressure centers and circulation patterns, raising questions about the quality of modeled wind-forced ice drift inferred from daily analysis products. 


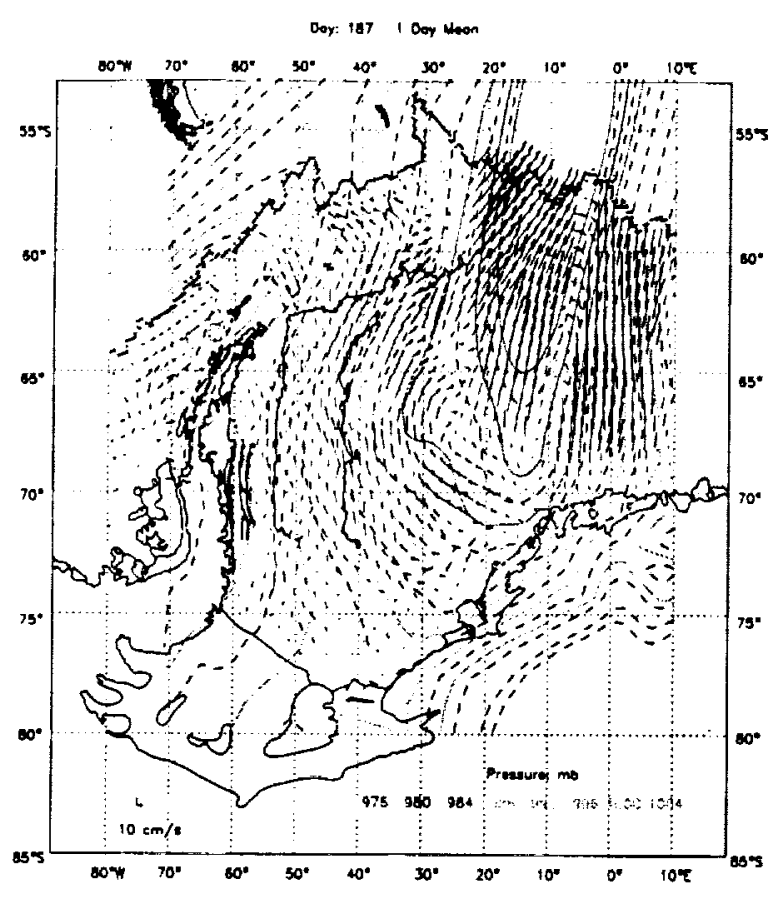

Figure 2. Weddell Sea 24 hour SSM/I ice motion and ECMWF surface air pressure field for day 187,1992 (July 5). Buoy vectors are highlighted in red

The seasonality of sea-ice dynamics is largely linked to the extent of the sea ice within the Weddell and Ross Sea basins and translation of internal ice stresses through the pack ice. Summaries of austral winter three-monthly climatologies of ice drift in the Ocean indicate lower mean summer drift speeds in response to relatively light winds. As winter progresses, the cyclonic isobaric circulation in the Weddell and Ross gyres becomes clearer. In both cases, sea ice accelerates as it

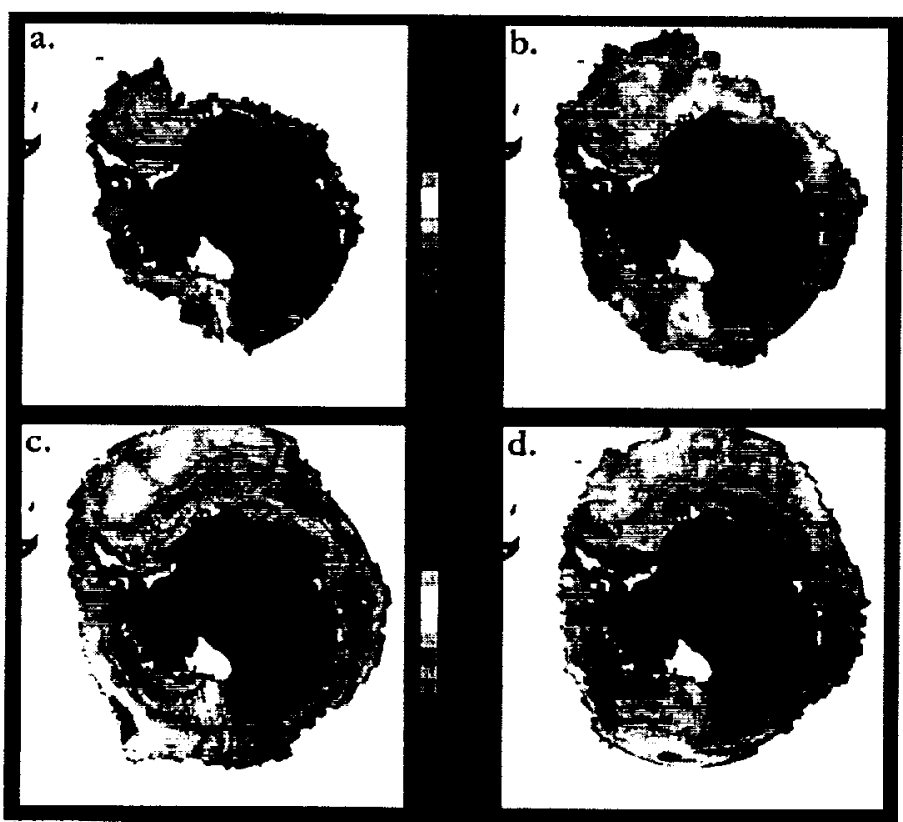

Figure 3. Climatological mean 1992 daily ice drift, derived from SSM/I $85 \mathrm{GHz}$ image data for (a) Jan-Mar; (b) Apr-Jun; (c) Jul-Sept (d) Oct-Dec. Colors indicate spatial variations in the drift speed and white arrows indicate drift streamlines. escapes the coastal entrapment of the Antarctic Peninsula and the Victoria Land coast to enter the Antarctic Circumpolar Current (ACC). The westward extent of the Ross Gyre is delinealed with ice leaving northwards to turn east and llow back towards the Amundsen Sea. A distinctive convergence zone occurs along the central axis of the Ross Sea $\left(-190^{\circ} \mathrm{E}\right)$ where large fractions of coastal perennial ice from the Amundsen Sea meet newly-formed ice forced northwards away from the Ross ice shelf by katabatic winds. Whereas the Ross Gyre indicates a seasonally variable southwards return limb in the Amundsen Sea, the Weddell gyre indicates no equivalent flow, with all perennial ice surviving the summer being swept from the basin the following year.

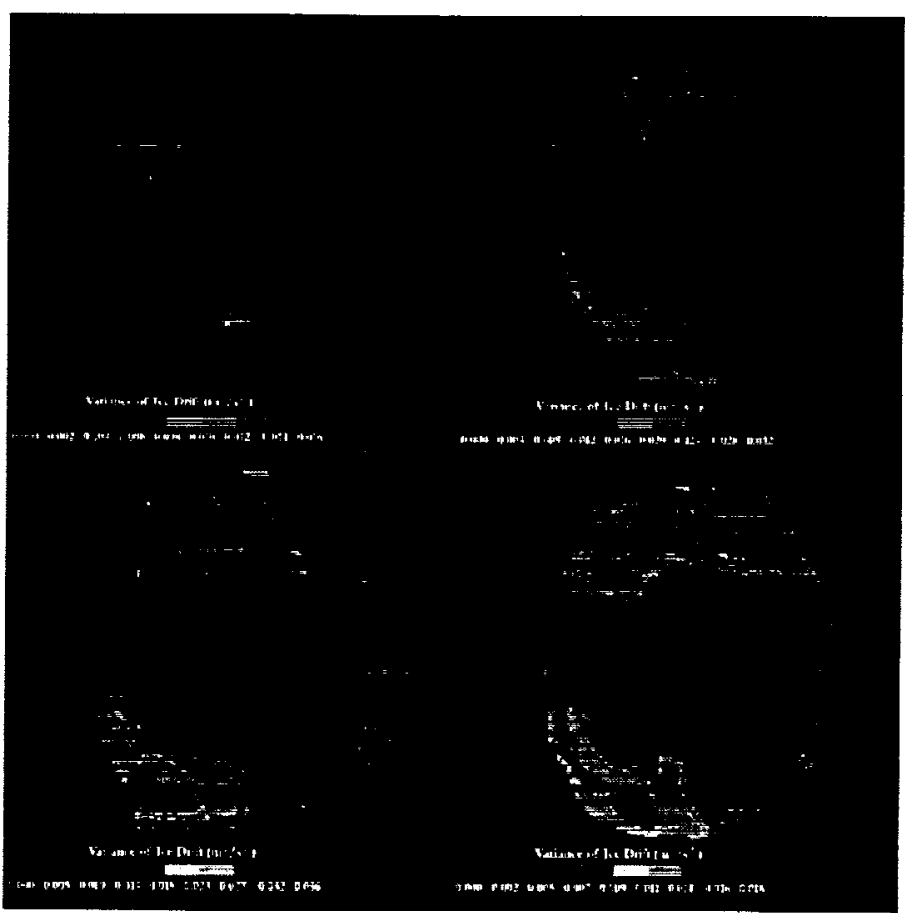

Figure 4. Seasonal variance in ice drift for same periods as in Figure 3.

As the seasonal ice advance takes place, the two zones of greatest ice drift variance in Fig. 4 migrate progressively northward and easiward out of each basin. These mid-winter zones have values $>2.0$ $\times 10^{-2} \mathrm{~m}^{2} / \mathrm{s}^{2}$ and occur slightly north of the Antarctic divergence, centered at $65^{\circ} \mathrm{S} 20^{\circ} \mathrm{W}$ and $65^{\circ} \mathrm{S} 140^{\circ} \mathrm{W}$, in the Weddell and Amundsen Seas respectively. The former is in a region where ice is forced to turn northwards as ice backs up in the western Weddell Sea, while the latter is in the region of most rapid ice drift with winter mean daily velocities exceeding $13 \mathrm{~km} \mathrm{~d}^{-1}$.

Time-series of ice dynamics parameters have been derived within specific regions to illustrate the correlation with meteorological forcing. Examples illustrate zones of consistent divergence and polynya formation, in contrast to convergence zones in which large fractions of deformed ice are found. High shear delineates the axis of the Antarctic divergence in many parts of the sea-ice cover. In these regions, the separation hetween the coastal east wind drift' and ACC. dominated drift regimes are characterized by zonally extended regions of intense shear. Other important zones of high shear occur at the western margin of the Ross Sea. Rapidly produced new ice exits the Terra Nova Bay polynya in the coastal current, with large shear values captured along the coast. In addition the largest winter shear strain is measured at the northern limb of the Ross Gyre where the highest drift velocitics are ohserved 
2

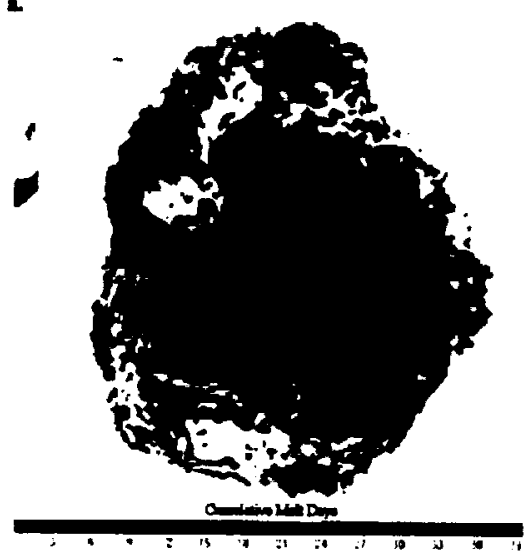

h.

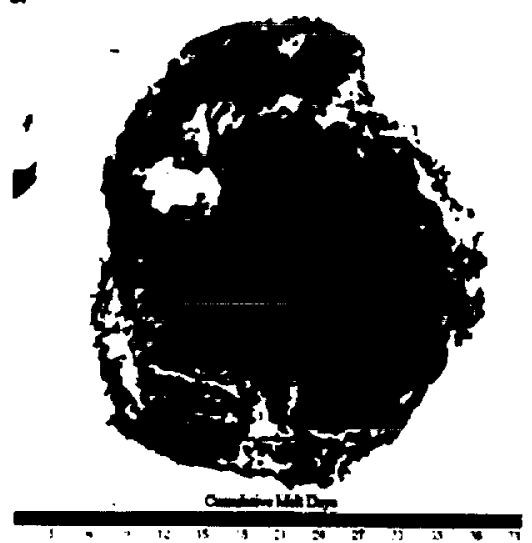

Figure 5. Cumulative surface melt days detected by (a) ERS-2, and (b) NSCAT data in the 1996-97 austral summer season.

\section{SEASONAL MELT}

Reference [12] recently demonstrated that austral summer ESCAT Antarctic images show melt characteristics similar to Arctic data. The backscarter is extremely sensitive to the appearance of liquid water in the snowpack at the time melting begins. Scatterometer time-series data were analyzed in conjunction with SMM/ to investigate austral summer melt during the period 1992-98. Onset of melting is characterized by an abrupt decline in backscatter, $\sigma_{w y}$ of $-3 \mathrm{~dB}$ or more over a contiguous time period exceeding several days. Here, a melt-detection algorithm was developed for general application to ESCAT or NSCAT data [12] and successively applied to all pixels within each image throughout the summer. Results indicate a polewand propagating melt front, moving progressively southwards with the seasonal air temperature increase. Although rapidly moving storms deliver sufficient heat to cause temporary surface melting, the scatterometer image record conclusively shows that summer surface melting is ephemeral. Instead of long periods with depressed backscatter coefficients, the summer is characterized by large fluctuations in $\sigma^{\circ}{ }_{v}$ indicating melting and freezing cycles [12]. The total cumulative melt days recorded by both instruments in Fig. 5 confirm that austral summer melting is short-lived, patchy and ephemeral. The only locations experiencing protracted vigorous melting (exceeding 30 days) in 1996-97 were regions bordering the Antarctic peninsula, in the Weddell and Bellingshausen Seas, and East Antarctic coastal regions. The southernmost melting region is observed in the Ross Sea, while the interesting point location located in the Amundsen Sea is discovered to correspond with the lacation of the large. drifting Thwaites iceberg (A-10).

\section{CONCLUSIONS}

Comparisons with meteorological analysis fields demonstrate that Antarctic sea-ice drift, tracked in $12-25 \mathrm{~km}$ resolution images, is forced predominantly by fluctuations in the large-scale geostrophic wind field varying on time-scales greater than days. Sub-daily variability is only successfully captured by hourly reporting GPS buoys or consistently repeated wide-swath SAR sea-ice tracking at intervals shorter than 12 hours. Synoptic scale sea-ice drift responds rapidly to changes in forcing on time-scales of 12 hours or less depending on the location with respect to the coastline. But, seasonality of ice drift velocity is linked to the extent of the ice in the Weddell and Ross Sea basins and the translation of internal stresses through the pack ice.

Austral summer melt results indicate that sea-ice extent appears predominantly a balance between atmosphericallydriven ice dynamics and ocean heat-flux. As meteorological forcing fields can be errant in their specification of the large-scale ice dynamics, many GCMs and process studies in Antarctica could be significantly improved simply by using a climatological, gridded ice drift fields which blend satellite and buoytracked ice motion data. Our next step is therefore to produce optimally-interpolated (satellite + buoy) Antarctic ice drift products for assimilation into the latest generation of fine-resolution models as more accurate boundary conditions.

\section{ACKNOWLEDGEMENT}

$\mathrm{MD}$ and $\mathrm{XI}$ performed this work at the Jet Propulsion Laboratory, California Institute of Technology, under contract to the National Aeronautics and Space Administration. Support was kindly provided by Prasad Gogineni of NASA Code $Y$.

\section{REFERENCES}

[1] Kottmeier, C., and L. Sellmann, Atmospheric and Oceanic Forcing of Weddell Sea Ice Motion, J. Geophys. Res., 101, C9, 20809-20824, 1996.

[2] Baranov, G.I., V.O. Ivchenko, M.I. Maslovskii, A.F. Treshnikov, and D.E. Kheisin, Wind Drift of Antarctic Sea Ice. In A.F. Treshnikov (Ed.) Problems of the Arctic and Antarctic, vol. 47. 136-159, 1976.

[3] Drinkwater, M.R, D.G. Long, and D.S. Early, Enhanced Resolution Scatterometer Imaging of Southern Ocean Sea Ice, ESA Joumal, 17, 307-322, 1993.

[4] Long, D.G., and M.R. Drinkwater, Cryosphere Applications of NSCAT Data, IEEE Trans. Geosci. and Remote Sens, In Press.

[5] Drinkwater, M.R., Satellite Microwave Radar Observations of Antarctic Sea Ice. In C. Tsatsoulis and R. Kwok (Eds.), Analysis of SAR Dasa of the Polar Oceans, 8, 147-187, Springer-Verlag, Berlin, 1998a.

[6] Drinkwater, M.R., Satellite Microwave Radar Observations of Climate-Related Sea-Ice Anomalies, Bull. Am. Met. Soc., Proc. Workshop on Polar Processes in Global Climate, 13-15 Nov., 1996, 115-118, 1997.

[7] Agnew, T., H. Le, T. Hirose, Estimation of Large-Scale Sea-Ice Motion from SSM/I 85.5 GHz Imagery, Ann. Glaciology. 25, 305-311, 1997.

[8] Emery, W.J., C.W. Fowler and J.A. Maslanik, Satellite-derived Maps of Arctic and Antarctic Sea Ice Motions: 1988-1994. Geophys. Res. Lett, 24, 897-900, 1997.

[9] Kwok. R., A. Schweiger, D.A. Rothrock , S. Pang, and C. Kottmeier, Sea Ice Motion from Satellite Passive Microwave Imagery Assessed with ERS SAR and Buoy Motions. J. Geophys. Res., 103, C4, 8191-8214, 1998.

[10] Maslanik, J.A., C. Fowler, J. Key, T. Scambos, T. Hutchinson. and W. Emery, AVHRR-based Polar Pathfinder Products for Modeling Applications, Ann. Glaciol., 25, 388-392, 1998.

[11] Liu, A., and D. J. Cavalieri, On Sea Ice Drift from the Wavelet Analysis of DMSP SSM/I data. Int. J. Remote Sens., 19, 7, 14151423, 1998.

[12] Drinkwater, M.R., P. Wadhams, D. Low, and X. Liu, Interannual Variability in Weddell Sea Ice from ERS Wind Scatterometer, ESA SP-424, 119-123. Nov. 1998. 